\title{
Bacterial aetiology of gastroenteritis in children; experience from a paediatric unit in a tertiary hospital of Sri Lanka
}

\author{
SHM Madubashini ${ }^{1}$, KSA Kottawatta ${ }^{1}$, ST Kudagammana ${ }^{2}$, RS Kalupahana ${ }^{1}$
}

\section{Introduction}

There is a paucity of data regarding bacterial aetiology of diarrheal illnesses in Sri Lanka, which is presumed to be mainly due to Shigella spp., Escherichia coli, Salmonella spp., and Campylobacter spp. We are presenting preliminary data of a comprehensive study conducted to identify the prevalence of the above bacteria and associated risk factors in causing diarrhoea in children.

\section{Methods}

Faecal samples from 100 patients with diarrhoea (age < 14 years) admitted to the professorial pediatric unit at Teaching Hospital Peradeniya and Sirimavo Bandaranayake Specialized Children's Hospital were tested for the presence of the above pathogens using ISO standard protocols. The species identification is being carried out utilizing serology and PCR. Antimicrobial susceptibility test was done according to CLSI guidelines (Clinical and Laboratory Standard Institute).

\section{Results}

Among the tested samples, 54 were positive for targeted bacterial species, five for other bacterial infections and 41 did not show significant bacterial growth. Escherichia coli was the most frequently identified organism (27\%). The pathogenic potential of these isolates is yet to be determined. Shigella spp. were the second most frequently isolated pathogen (15\%). Salmonella spp. were isolated from $6(6 \%)$. Campylobacter was notably absent in any of the samples. Combinations of two of the tested pathogens were detected in 6 samples. Among the tested age groups, the highest number of patients were in the 1-3 year age group (40\%).

\section{Conclusions}

The results generated through this preliminary study indicate the importance of continuing this study as such results will be helpful for clinicians and public health personnel for correct planning of therapeutic and preventive strategies.

Keywords: Diarrhoea, Shigella, Campylobacter, E. coli, Salmonella

\footnotetext{
${ }^{I}$ Department of Veterinary Public Health and Pharmacology, Faculty of Veterinary Medicine and Animal Science, University of Peradeniya, Sri Lanka

${ }^{2}$ Department of Paediatrics, Faculty of Medicine, University of Peradeniya, Sri Lanka

Address for correspondence: SHM Madubashini. Telephone: +94712840736 Email: shmihiri617@gmail.com iD https://orcid.org/0000-0002-0413-8731
} 